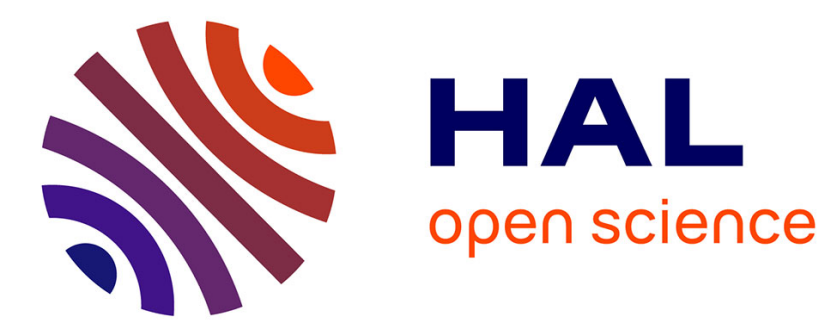

\title{
Experimental electron densities of neutral and zwitterionic forms of piroxicam drug
}

Xiaoxuan Shi, Nouha El Hassan, Aziza Ikni, Wenjing Li, N. Guiblin, A. Spasojević De-Biré, N. Ghermani

\section{- To cite this version:}

Xiaoxuan Shi, Nouha El Hassan, Aziza Ikni, Wenjing Li, N. Guiblin, et al.. Experimental electron densities of neutral and zwitterionic forms of piroxicam drug. CrystEngComm, 2016, 18 (18), pp.3289 - 3299. 10.1039/C5CE02397A . hal-01782546

\section{HAL Id: hal-01782546 \\ https://hal.science/hal-01782546}

Submitted on 29 Sep 2020

HAL is a multi-disciplinary open access archive for the deposit and dissemination of scientific research documents, whether they are published or not. The documents may come from teaching and research institutions in France or abroad, or from public or private research centers.
L'archive ouverte pluridisciplinaire HAL, est destinée au dépôt et à la diffusion de documents scientifiques de niveau recherche, publiés ou non, émanant des établissements d'enseignement et de recherche français ou étrangers, des laboratoires publics ou privés. 


\title{
Experimental electron densities of neutral and zwitterionic forms of piroxicam drug
}

\author{
X. Shi, ${ }^{a}$ N. El Hassan, ${ }^{a}$ A. Ikni, ${ }^{a}$ W. Li, ${ }^{a}$ N. Guiblin, ${ }^{a}$ A. Spasojević de-Biré ${ }^{a}$ and N.E. Ghermani, ${ }^{a, b, *}$
}

The electron and electrostatic properties of piroxicam (PX) were derived from high resolution X-ray diffraction experiments carried out at 100 $K$. Two forms of the piroxicam molecule have been investigated in their crystalline states. One molecule is neutral (nPX) in form I (monoclinic) of piroxicam, while the second found in the hydrated pseudopolymorph (triclinic) is zwitterionic (zPX). In the zPX crystal, the asymmetric unit is formed by two PX molecules with different conformations. The experimental electron density was refined using the Hansen-Coppens multipole model. The electron densities were carefully analyzed using the Atoms in Molecules approach of Richard Bader. Integrated atomic charges compare well for the $\mathrm{nPX}$ and $\mathrm{zPX}$ molecules. The negative electrostatic potential is found more extended for the $\mathrm{zPX}$ molecules than in the $\mathrm{nPX}$ one, probably due to the presence of the water molecules connected via hydrogen bonds. The electrostatic potential values on the molecular surface (isodensity of 0.007 e $\AA^{-3}$ ) were statistically analyzed in order to reveal local polarity, variances of the positive and negative regions, charge separation etc. In the $\mathrm{nPX}$ crystal, the molecular dipole is found equal to $9.12 \mathrm{D}$ with a local dipole of $9.28 \mathrm{D}$ for the $\mathrm{SO}_{2} \mathrm{CN}$ fragment. The two molecules in the asymmetric unit of the $\mathrm{zPX}$ crystal display dipole moment magnitudes respectively equal to $6.83 \mathrm{D}$ and $22.69 \mathrm{D}$; the corresponding $\mathrm{SO}_{2} \mathrm{CN}$ sulfonyl cyanide fragment dipoles are 10.88 D and 13.64 D. Comparisons were made for the same fragment in the sulfathiazole molecule. Hence, we have also studied the polymorphs III and IV of the sulfathiazole; the asymmetric unit for polymorph III contains two molecules. The resulted $\mathrm{SO}_{2} \mathrm{CN}$ dipole moment values are $11.19 \mathrm{D}$ and $11.18 \mathrm{D}$ found for the two molecules in polymorph III and $12.34 \mathrm{D}$ for polymorph IV of the sulfathiazole. The intermolecular electrostatic interaction and the empirical packing energies are estimated to characterize the crystal packing of the two forms of piroxicam.

\section{Introduction}

Nowadays, high resolution X-ray diffraction experiments yield very accurate data permitting a precise description of the electron density of molecules in the crystal lattice. This electron density can be carefully analyzed through its topological features to reveal the nature of atomic bonds: covalent, van der Waals, aromatic, hydrogen, metallic and so on. For this purpose, Atoms In Molecules (AIM) theory of Bader ${ }^{1}$ is generally applied and is based on the features of the

\footnotetext{
a. Laboratoire Structures, Propriétés et Modélisation des Solides, Université Paris Saclay, CentraleSupélec, CNRS; Grande voie des vignes, 92295 Châtenay-Malabry, France.

b. Laboratoire de Physique Pharmaceutique, Institut Galien Paris Sud, UMR CNRS 8612, Université Paris Sud, Faculté de Pharmacie ; 5, rue Jean-Baptiste Clément, 92296 Châtenay-Malabry, France.

E-mail address: noureddine.ghermani@u-psud.fr; Fax: +33 (0)1 4683 58 82; Tel: +33(0)146835648

+ Electronic supplementary information (ESI) available:CIF files deposit (CCDC): $n P X$ (1430948), zPX (1430947), sulfathiazole III (1430949), sulfathiazole IV (1430950).

Table S1. Conformations and configurations of the piroxicam molecules. Figures S1 to S6, residual density, deformation density, Laplacian of the electron density and molecular surfaces colored by the electrostatic potential for piroxicam and sulfathiazole in the four crystal structures. See DOI: 10.1039/x0xx00000x
}

gradient and the Laplacian of the electron distribution. For organic compounds, the experimental molecular electron density obtained in the crystal is very comparable to that obtained by high-level quantum mechanics calculations as we recently show for carbamazepine. ${ }^{2}$ It means that the electrostatic properties of molecules in the crystal lattice do not significantly change in other media; except when strong external fields due to polar solvents or $\mathrm{pH}^{\prime} \mathrm{s}$ can affect the molecular electron density. This makes the high resolution $\mathrm{X}$ ray diffraction experiment a powerful tool to study the structure-activity and the chemical reactivity of molecules. This approach is especially important for the development of drugs and the understanding of their specific biological activities. In this field, the crystalline polymorphism exhibited by API's (Active Pharmaceutical Ingredients) can have crucial impacts on oral absorption and bioavailability of numerous drugs. The most known example is that of Ritonavir (Norvir ${ }^{\circledR}$, Abbot) used to treat HIV disease and which, after months, precipitates inside the gelatin capsules in the less soluble and undesired form II. ${ }^{3}$

The purpose of this study is to characterize the electron density of piroxicam (PX) molecule, (4-Hydroxy-2-methyl-N-(2pyridinyl)-2H-1,2-benzothiazine-3-carboxamide 1,1-dioxide) 
(scheme 1) in neutral (nPX) and zwitterionic (zPX) states. In the last case, the intramolecular proton transfer yields significant changes in the molecular conformation. Piroxicam is a well known non-steroidal anti-inflammatory drug (NSAID) which is used for fever, pain (rheumatoid arthritis and osteoarthritis) and inflammation. It was known from the 80 's that its biological mechanism of action is the inhibition of the prostaglandin biosyntheses ${ }^{4}$ and for cancer chemoprevention. ${ }^{5}$ The bioavailability problem arises from its low water solubility and dissolution rate in the acid medium in which the absorption takes place. Oral piroxicam administration is characterized by a slow absorption. ${ }^{6}$ According to Yazdanian et al., ${ }^{7}$ piroxicam belongs to Class I in Biopharmaceutics Classification System. ${ }^{8}$ While based on its low water solubility and high permeability, Gwak et al. ${ }^{9}$ have suggested that piroxicam could be classified as a Class II drug. In the crystalline state, piroxicam exhibits three polymorphs (I, II, III) and a monohydrate with the zwitterionic PX. ${ }^{10-13}$ Recently a new polymorph has been identified. ${ }^{14}$ All the polymorphic crystals of PX are colorless whereas the hydrated pseudopolymorph is yellow. This yellow color is the signature of the presence of the ionized state of PX. This was carefully quantified in amorphous PX or crystalline PX under mechanical stress by spectroscopic methods and ${ }^{13} \mathrm{C}$ NMR. ${ }^{15}$ The polymorph crystal color was attributed by the authors to the change of the molecular conformation and to the hydrogen bondings. ${ }^{15}$ Proton transfer and polymorphism in co-crystals have also been extensively investigated for complexes of PX with mono-substituted benzoic acids, with carboxylic acids ${ }^{16-17}$ or various organic species. ${ }^{18-20}$ In the case of cocrystal of $\mathrm{PX} /$ fumaric acid, both forms of PX were found in the asymmetric unit but, interestingly, only the neutral form of PX interacts with the fumaric acid; the ionized molecules are separately grouped in dimers. ${ }^{17}$ Atom numbering of the neutral and the PX charged forms used in this paper are presented in Scheme 1. PX could present different configurations according to the existence of three rotatable bonds (C1-C10, C10-N2, N2-C11) (red arrows, Scheme 1). Following IUPAC rules, ${ }^{17 b i s}$ three different configurations have crystallized in the solid state: $1 E, 10 Z, 2 Z ; 1 Z, 10 Z, 2 Z$ and $1 Z$, $10 Z, 2 E$. For sake of clarity these configurations will be named as EZE, ZZZ and ZZE, the numbers being omitted (scheme 2). Atoms concerned by the proton position are indicated in parentheses. The number of crystal structures found in the CSD is indicated in parentheses. ${ }^{19}$

In the present study, we report the structural and electronic properties of the two forms of PX, nPX (neutral piroxicam) and $\mathrm{zPX}$ (zwitterionic piroxicam). The electron densities were derived from accurate high resolution low temperature X-ray diffraction data. The electron densities were carefully analyzed using the topological AIM method. ${ }^{1}$ The atomic charges, dipole moments and electrostatic potential are presented in this paper. A particular attention was paid to the sulfonyl cyanide $\mathrm{SO}_{2} \mathrm{CN}$ fragment which is also present in the sulfathiazole molecule, a local antimicrobial agent, for which we possess our own experimental electron density. Recently, the electron topological properties of 4 polymorphs (I-IV) of sulfathiazole was independently published. $^{21}$ More than 100 forms are described for sulfathiazole. $^{22}$ The statistical analysis of the electrostatic potential on the molecular surface as initiated by Politzer et al. has also been made for PX molecules. ${ }^{23-26}$ This gives a quantitative description of the electrostatic potential on the molecular surface. Finally, the intermolecular interactions are characterized by the electrostatic energies. (a)

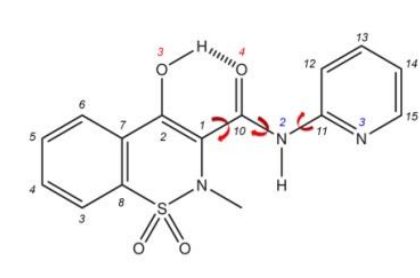

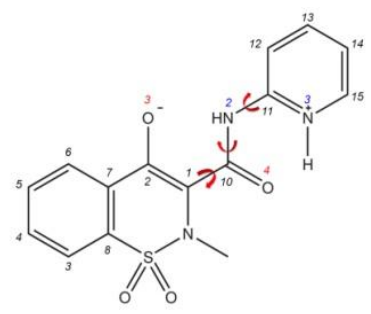

(b)
Scheme 1 Atom numbering of the neutral and zwitterionic PX forms used in this paper (carbon in black, nitrogen in blue, oxygen in red). The 3 rotatable bonds $\mathrm{C} 1-\mathrm{C} 10, \mathrm{C} 10-$ N2 and N2-C11. a) Neutral form; b) zwitterionic form.

\section{Experimental and methodological section}

\section{Crystallization}

Crystal samples used in this study were obtained by slow evaporation of supersaturated solutions of piroxicam. Several solvent were tested to examine all possibilities of crystallization. Crystals of piroxicam form I (nPX) were obtained in acetonitrile solvent and those of the monohydrated piroxicam ( $\mathrm{ZPX}$ ) in $3: 1$ volume mixture of acetonitrile and water. They both display multi-surface prismatic morphology, the former is colorless and the latter is yellow. The crystal forms of these two compounds were identified by their unit cell parameters according to the published structures. ${ }^{11,27}$

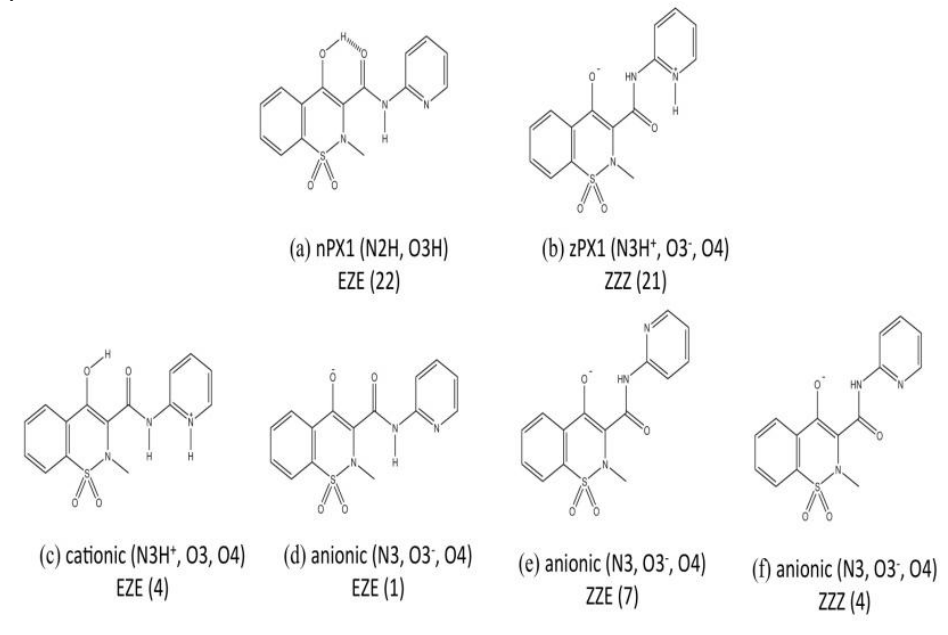

Scheme 2 Neutral form, zwitterionic form, cationic form and 3 different conformations (ZZZ, EZZ and EZE) of anionic form found in crystal structures respectively from (a) to (f). Atoms concerned by the proton position are indicated in parentheses. The number of crystal structures found in the CSD is indicated in parentheses. ${ }^{19}$ 


\section{X-ray data collections}

The data for $\mathrm{nPX}$ and $\mathrm{zPX}$ crystals were collected at $100 \mathrm{~K}$ on a Bruker-D8 Venture four axis diffractometer equipped with a Photon 100 detector using graphite monochromated MoK $\alpha$ Xradiation (wavelength $\lambda=0.71069 \AA$ ). The data spots were recorded as $\omega^{\text {-scans }}\left(\Delta \omega=0.5^{\circ}\right)$ in order to reconstruct accurate three dimensional diffracted intensity peak profiles. According to the $\theta$-dependence of the diffracted intensities, different exposure time strategies were used. For the nPX compound, 5 seconds (low Bragg angles) and 10 seconds (high Bragg angles) were applied; for ZPX compound, exposure time was varied from 10 seconds (low Bragg angles) to 15 seconds (high Bragg angles). The maximum resolution reached for these experiments are $\sin \theta_{\max } / \lambda=H / 2=1.21 \AA^{-1}$, where $\mathrm{H}$ is the Bragg vector modulus. Integration of the diffracted intensities and an empirical absorption correction were performed using APEX2 software ${ }^{28}$ suite which includes SADABS computer program for absorption correction. SORTAV $^{29}$ program was used for sorting and averaging data. Details of the $\mathrm{X}$-ray diffraction experiment conditions are given in Table 1.

\section{Spherical and electron density refinements}

The four crystal structures were solved using SIR92 program $^{30}$ and refined using SHELX ${ }^{31}$ implemented in WinGX ${ }^{32}$ package. Hansen-Coppens aspherical model ${ }^{33}$ was applied for the electron density refinements. The frozen core and normalized spherical valence densities are determined using the HartreeFock wave functions of the free atoms or ions. ${ }^{34}$ The contraction-expansion coefficient $\kappa$ and the corresponding refined electron population Pval are used for a more precise spherical description. The aspherical part of the pseudo-atom electron density is projected onto a set of real normalized harmonic basis set $(I=0$ (monopole) to 4 (hexadecapole)) and modulated by a Slater-type radial function $R_{n l} \quad r=N r^{n_{l}} \exp -\xi_{l} r$, where $\mathrm{N}$ is a normalization factor. The exponents ${ }^{35} \xi_{1}$ (in bohr $r^{-1}$ ) of the radial functions are chosen contraction-expansion coefficient used to adjust the maximum of the radial function of the multipole expansion. MoPro program $^{37,38}$ was used for the electron density refinement against all the structure factors $F$ with no statistical standard deviations based cut-off $(I>0)$. Indeed, this program combines both conventional and conjugated gradient least-square procedures and requires all observed diffraction intensities. High-order refinement using data with resolution $\sin \theta / \lambda>0.8^{-1}$ was performed for accurate atomic positions and atomic displacement parameters of non hydrogen atoms in the first cycles of the refinements. The hydrogen anisotropic thermal displacements parameters (ADPs) were obtained from SHADE2 analysis for both compounds of piroxicam. ${ }^{39}$ equal to 3.8 and $n_{1}$ $=2,4,6,8$ up to hexadecapoles $(I=4)$ for $S$ atom; ${ }^{36} \xi_{1}=3.2$, 4.5, 3.8 bohr $^{-1}$ and $n_{1}=2,2,3$ up to octupoles $(I=3)$ for $C, O$ and $\mathrm{N}$ atoms, respectively; $\xi_{1}=2.00 \mathrm{bohr}^{-1}$ and $\mathrm{n}_{1}=1$ (dipole level, $I=1$ ) for the hydrogen atoms. $\kappa^{\prime}$ is a

\section{Topological analysis of the experimental electron density}

The analysis of the topological features of the electron density was carried out following the AIM (Atoms in Molecules) theory. ${ }^{1}$ The AIM approach is a model used for the characterization of the chemical bonding and the electronic structure of atoms in molecules. The atomic basin enclosed by zero-flux surfaces $(\nabla \rho(r) \cdot n(r)=0)$ is used for separating the electron density distribution between atoms. On these surfaces, the critical points (CP) corresponding to the extrema and saddle points of $\rho(r)$ are characterized by two numbers: the number of the eigenvalues (for non-degenerating cases) and the signature of the eigenvalues triplet $\left(\lambda_{1}, \lambda_{2}, \lambda_{3}\right)$. The ellipticity defined by $\varepsilon=\left(\lambda_{1}-\lambda_{2}\right) / \lambda_{2}$ is an index of the type of the chemical bonds ( $\sigma$ or $\pi$ ).

\section{Experimental electrostatic potential and interaction energies}

VMoPro $^{37,} 38$ computer program was used to generate the electrostatic potential based on the Hansen-Coppens electron density model. ${ }^{33}$ The electrostatic potential exhibits the nucleophilic (negative potential) and electrophilic (positive 
potential) regions of the molecule and is a good indicator of the chemical reactivity. The electrostatic potential projected on a well-defined surface (for instance an isodensity surface) is a common qualitative indicator of the molecular chemical reactivity. For quantitative interpretation, several statisticallydefined quantities have been introduced by Politzer et al. ${ }^{23-26}$ to characterize the surface potential, including: i) positive $\overline{\mathrm{V}}_{\mathrm{S}}^{+}$, negative $\overline{\mathbf{V}}_{\mathrm{S}}^{-}$and overall average potentials on the surface $\overline{\mathrm{V}}_{\mathrm{s}}$; ii) average deviation $\Pi$ which indicates the local polarity; iii) positive, negative and total variances $\sigma_{+}^{2}, \sigma_{-}^{2}$ and $\sigma_{\text {tot }}^{2}$; iv) $v$ which is a degree of balance between the positive and negative surface potentials (its maximum equal to 0.25 is reached when $\left.\sigma_{+}^{2}=\sigma_{-}^{2}\right) .{ }^{24}$ These quantities explicitly reflect the magnitude of $V_{S}$ at each point and can be used to characterize the non-covalent interactions. ${ }^{23-26}$

$$
\begin{gathered}
\sigma_{\mathrm{tot}}^{2}=\sigma_{+}^{2}+\sigma_{-}^{2}=\frac{1}{\mathrm{~m}} \sum_{i=1}^{\mathrm{m}} \boldsymbol{V}^{+}\left(\boldsymbol{r}_{\mathrm{i}}\right)-\overline{\mathrm{V}}_{\mathrm{S}}^{+}{ }^{2}+\frac{1}{\mathrm{n}} \sum_{j=1}^{\mathrm{n}}\left(\mathrm{V}^{-}\left(\boldsymbol{r}_{\mathrm{j}}\right)-\overline{\mathrm{V}}_{\mathrm{S}}^{-}\right)^{2} \\
\Pi=\frac{1}{\mathrm{~m}+\mathrm{n}} \sum_{i=1}^{\mathrm{m}+\mathrm{n}}\left|\mathrm{V}\left(\boldsymbol{r}_{\mathrm{i}}\right)-\overline{\mathrm{V}}_{\mathrm{S}}\right| \\
v=\frac{\sigma_{+}^{2} \sigma_{-}^{2}}{\mathbf{G}_{\mathrm{tot}}^{2}}
\end{gathered}
$$

Here, $m$ and $n$ are the number of grid points where the electrostatic potential is positive $(+)$ and negative $(-)$, respectively.

Finally, the electrostatic interaction energy ${ }^{37,38} \mathrm{E}_{\text {elec }}$ between two charge distributions $A$ (through its charge density $\rho_{A}$ ) and $B$ (through its electrostatic potential $V_{B}$ ) is estimated by the integral of $\rho_{A} \cdot V_{B}, A$ and $B$ can be chosen as fragments or entire molecules.

\section{Results and discussion}

\section{Crystal structures}

Molecular structures of $\mathrm{nPX}$ (form I) and zPX (hydrated PX) molecules are given in Figure 1. Form I of PX crystallizes in monoclinic $\mathrm{P} 2_{1} / c$ space group and the $\mathrm{ZPX}$ in the triclinic $\mathrm{P}^{\overline{1}}$. The atomic positions and ADP's were first refined using SHELX program. ${ }^{31}$ The values of these parameters were then improved after the multipole refinements. ${ }^{33,37,38}$ Table 2 gives a selected set of bond distances and angles obtained after the multipole refinements of the crystallographic data. The $n P X$ molecule and the two molecules labeled R (right) and L (left) of the asymmetric unit in $\mathrm{ZPX}$ are characterized by particular dihedral angles: O4-C10-C1-N1 $=174.37(2)^{\circ}(\mathrm{nPX}),-2.32(2)^{\circ}$ $(z P X L)$ and $-0.22(2)^{\circ}(z P X R) ; N 3-C 11-N 2-C 10=-176.78(3)^{\circ}$ $(n P X),-14.74(1)^{\circ}(z P X L)$ and $-6.55(1)^{\circ}(z P X R) ; C 1-C 10-N 2-C 11=$ $-176.71(3)^{\circ}(n P X),-175.93(2)^{\circ}(z P X L)$ and $-170.08(2)^{\circ}(z P X R)$. The proton transfer in zPX molecules has also an impact on the bond distances: $\mathrm{C} 2-\mathrm{O} 3=1.3327(5) \AA(n P X), 1.2676(1) \AA(\mathrm{zPXL})$ and 1.2768(1) $\AA$ ( $(\mathrm{PXXR}) ; \mathrm{C} 10-\mathrm{N} 2=1.3557(6) \AA$ (nPX), 1.3917(1)

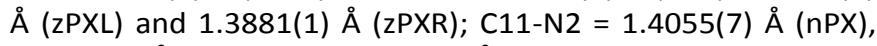
$1.3536(1) \AA ̊(z P X L)$ and $1.3637(1) \AA(z P X R) ; C 1-C 10=1.4692(8)$

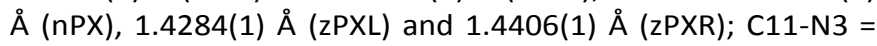
$1.3368(5) \AA(n P X), 1.3462(1) \AA ̊(z P X L)$ and $1.3444(1) \AA(z P X R)$; $\mathrm{C} 15-\mathrm{N} 3=1.3397(7) \AA$ (nPX), 1.3554(1) $\AA$ (zPXL) and 1.3552(1)

\begin{tabular}{|c|c|c|}
\hline Compound formula & $\mathrm{C}_{15} \mathrm{H}_{13} \mathrm{~N}_{3} \mathrm{O}_{4} \mathrm{~S}$ & $\mathrm{C}_{15} \mathrm{H}_{13} \mathrm{~N}_{3} \mathrm{O}_{4} \mathrm{~S} \cdot \mathrm{H}_{2} \mathrm{O}$ \\
\hline Polymorph & $\mathrm{I}(\mathrm{nPX})$ & hydrated (zPX) \\
\hline Formula weight & 330.34 & 348.3553 \\
\hline Crystal system & monoclinic & triclinic \\
\hline Space group & $\mathrm{P} 2_{1} / \mathrm{c}$ & $\mathrm{P}-1$ \\
\hline$a(\AA)$ & $7.0306(2)$ & $10.3302(6)$ \\
\hline$b(\AA)$ & $14.9750(4)$ & $12.7044(7)$ \\
\hline$c(\AA)$ & $13.8923(4)$ & $12.7984(7)$ \\
\hline$\alpha\left({ }^{\circ}\right)$ & 90 & $102.776(2)$ \\
\hline$\beta\left(^{\circ}\right)$ & $96.408(1)$ & $99.919(2)$ \\
\hline$\gamma\left({ }^{\circ}\right)$ & 90 & $108.760(2)$ \\
\hline$V\left(\AA^{3}\right)$ & $1453.49(8)$ & $1496.20(15)$ \\
\hline $\mathrm{Z}$ & 4 & 4 \\
\hline$D_{\text {calc }}\left(\mathrm{g} \mathrm{cm}^{-3}\right)$ & 1.510 & 1.542 \\
\hline$\lambda(\AA)$ & 0.71069 & 0.71069 \\
\hline$\mu\left(\mathrm{mm}^{-1}\right)$ & 0.248 & 0.257 \\
\hline Temperature (K) & $100(2)$ & $100(2)$ \\
\hline$\theta \operatorname{range}\left(^{\circ}\right)$ & 2.72 to 59.39 & 2.77 to 59.09 \\
\hline$(\sin \theta / \lambda)_{\max }\left(\AA^{-1}\right)$ & 1.21 & 1.21 \\
\hline Average redundancy & 11.5 & 4.8 \\
\hline Completeness & $99.2 \%$ & $97.8 \%$ \\
\hline Reflections collected & 245692 & 206394 \\
\hline Independent reflections & 21208 & 43123 \\
\hline \multirow[t]{3}{*}{ hkl range } & $-16 \leq \mathrm{h} \leq 16$ & $-22 \leq \mathrm{h} \leq 24$ \\
\hline & $-36 \leq \mathrm{k} \leq 36$ & $-30 \leq \mathrm{k} \leq 30$ \\
\hline & $-33 \leq 1 \leq 33$ & $-30 \leq 1 \leq 30$ \\
\hline $\mathrm{R}_{\mathrm{int}}$ & 0.0568 & 0.0344 \\
\hline \multicolumn{3}{|l|}{$\begin{array}{l}\text { Spherical atom } \\
\text { refinement: }\end{array}$} \\
\hline no. of data in refinement & 21208 & 43123 \\
\hline no. of refined parameters & 209 & 447 \\
\hline $\begin{array}{l}\text { no. of reflect. used [I > } \\
2 \sigma(\mathrm{I})]\end{array}$ & 14440 & 29818 \\
\hline $\mathrm{R}(\mathrm{F}) / \mathrm{wR}(\mathrm{F})$ & $0.0472 / 0.1368$ & $0.0503 / 0.1658$ \\
\hline Goodness of fit & 1.051 & 1.212 \\
\hline \multicolumn{3}{|l|}{ Multipole refinement: } \\
\hline no. of reflection used & 10483 & 25088 \\
\hline no. of refined parameters & 247 & 527 \\
\hline $\mathrm{R}(\mathrm{F}) / \mathrm{wR}(\mathrm{F})$ & $0.024 / 0.019$ & $0.026 / 0.020$ \\
\hline Goodness of fit & 0.615 & 0.981 \\
\hline
\end{tabular}
(zPXR). C2-O3 and N2-C11 simple bonds are shortened Table 1 Crystal Data and refinement Details. towards $\mathrm{C} 10-\mathrm{O} 4$ and $\mathrm{N} 3-\mathrm{C} 11$ respectively whereas $\mathrm{C} 1-\mathrm{C} 2$ double bond is extended towards C1-C10 simple bond. These observations indicate the existence of an electron delocalization along the chain $(\mathrm{O} 3, \mathrm{C} 2, \mathrm{C} 1, \mathrm{C} 10, \mathrm{~N} 2, \mathrm{C} 11)$ in zwitterionic form. Figure 2 displays the intramolecular and intermolecular hydrogen bonds found in the crystal lattices of $\mathrm{nPX}$ and $\mathrm{zPX}$. The intramolecular hydrogen bonds involves $\mathrm{O} 3$ and $\mathrm{O} 4(\mathrm{H} 3 \mathrm{O} \ldots \mathrm{O} 4=1.730(2) \AA$ ) in $\mathrm{nPX}$ molecule and $\mathrm{N} 2$ and $\mathrm{O} 3$ $(\mathrm{H} 2 \mathrm{NL} \ldots \mathrm{OO} \mathrm{L}=1.714(2) \AA, \mathrm{H} 2 \mathrm{NR} \ldots \mathrm{O} 3 \mathrm{R}=1.780(2) \AA)$ in $\mathrm{zPX}$ molecules. In the nPX crystal, the molecules are grouped in dimers as shown in Figure 2. In the other crystal, four zPX molecules are connected through hydrogen bonds, two zPXL and two zPXR. Only one water molecule (O5B in Figure 2), among the two in the asymmetric unit, is linked to $z P X$ molecules (O5B-H5OB...O3R $=1.838(2) \AA$, O5B-H6OB $\ldots$ O $4 \mathrm{~L}=$ $1.882(1) \AA$; the other $(\mathrm{O} 5 \mathrm{~A})$ is connected to the former (O5A- 
H5OA...O5B $=1.982(1) \AA ̊$ ). Table 2 also lists the main features of the hydrogen bond networks in the crystal lattices of the two compounds.
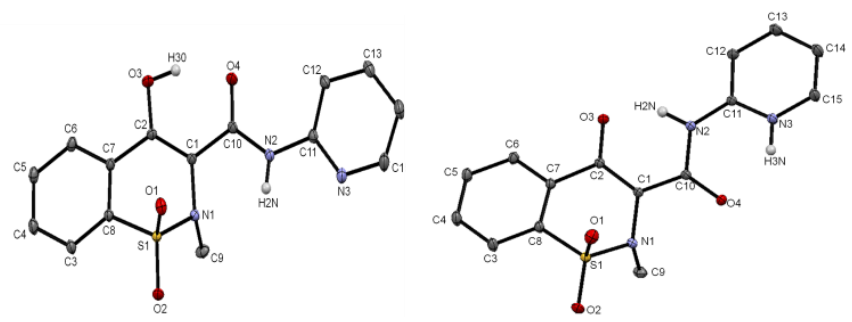

Fig. 1 Molecular structures of nPX (left) and zPX (right) molecules. Hydrogen atoms are omitted for clarity except in $\mathrm{N}-\mathrm{H}$ and $\mathrm{O}-\mathrm{H}$ bonds.

\section{Electron deformation density and topological analysis}

The electron deformation distribution, as calculated from the Hansen-Coppens model, ${ }^{33}$ is shown in Figure 3 . This Figure illustrates the static electron deformation density of $\mathrm{nPX}$ molecule which is similar to those of the two zPX molecules. Sigma bonds for

Table 2 Hydrogen bond geometrical characteristics, $D$ is the donor and A, the acceptor.

$\begin{array}{llll}\text { H-bonds nPX } & \text { symmetry } & \text { H...A } & \text { D...A } \\ \text { O3-H3O...O4 } & x, y, z & 1.730(2) & 2.561(1) \\ \text { N2-H2N...O2 } & 2-x,-y,-z & 2.301(2) & 2.999(2) \\ & & & \\ \text { H-bonds zPX } & & & \\ \text { N2L-H2NL...O3L } & x, y, z & 1.713(2) & 2.5300(1) \\ \text { N2R-H2NR...O3R } & x, y, z & 1.780(2) & 2.5873(1) \\ \text { N3L-H3NL...O4L } & x, y, z & 1.987(2) & 2.6732(2) \\ \text { N3R-H3NR...O1L } & x, y, z & 2.561(1) & 2.9396(2) \\ \text { N3R-H3NR...O4R } & x, y, z & 1.924(2) & 2.6501(2) \\ \text { O5B-H5OB...O3R } & x, y, z & 1.838(2) & 2.7522(1) \\ \text { O5B -H6OB...O4L } & x, y, 1+z & 1.882(1) & 2.8075(2) \\ \text { O5A -H5OA...O5B } & 1-x, 1-y, 1-z & 1.982(1) & 2.9134(2) \\ \text { N3L -H3NL...O4R } & 2-x, 1-y,-z & 2.052(1) & 2.7824(1) \\ \text { N3R -H3NR...O4L } & 2-x, 1-y,-z & 2.207(1) & 2.8857(1)\end{array}$

$\mathrm{C}-\mathrm{C}, \mathrm{C}-\mathrm{N}, \mathrm{C}=\mathrm{O}$ and $\mathrm{C}-\mathrm{H}$ are clearly revealed by the overlap of the atomic electron densities of the connected atoms. In Figure 3 , we can also see the polarizations of the lone pairs of N3, O3 and $\mathrm{O} 4$ atoms. The electron densities of the oxygen atoms $\mathrm{O} 1$ and $\mathrm{O} 2$ of the sulfonyl cyanide fragment exhibit, however, a quasi-cylindrical shape. The negative deformation electron density regions are found surrounding the sigma bonds and in the middle of the rings. These regions correspond to the depletion of the electron density i.e. the reduction of the electron density over the sum of the spherical atomic densities.

We have applied the topological analysis to the total electron density following the theory of Bader. ${ }^{1}$ Figure 4 depicts the three dimensional representation of the Laplacian of the electron density for the $\mathrm{nPX}$ molecule, the features of $\mathrm{ZPX}$ molecules being very similar. For sake of clarity, only two isosufaces were chosen corresponding to $\pm 0.3 \mathrm{e}^{-5}$ values. For carbon and hydrogen atoms, the positive Laplacian isosurface has a spherical shape and surrounds the atomic nuclei. For $\mathrm{O} 1, \mathrm{O} 2, \mathrm{O} 3$ and $\mathrm{O} 4$ atoms, the positive isosurface corresponding to $+0.3 \mathrm{eA}^{-5}$ is also present externally to the lone pairs but without features of electronic polarization. In contrast, for $\mathrm{N}$ atoms, three positive lobes surround $\mathrm{N} 1, \mathrm{~N} 2$ and N3 which reveal the octupolar deformation of the electron density. The negative Laplacian isosurfaces present more variations: i) the covalent $\mathrm{C}-\mathrm{C}$ bonds are characterized by a cylindrical saddle form, for heteroatom bonds like $\mathrm{C}-\mathrm{N}, \mathrm{C}=\mathrm{O}$ and $\mathrm{C}-$ $\mathrm{H}$, the form becomes asymmetric; ii) the lone pair of N3 nitrogen atom is clearly revealed in the plane of the pyridine ring. The quantitative topological characteristics of the electron density of the studied molecules are reported in Table 3 . For all bonds within a given organic molecule, the Laplacian $\left[\nabla^{2} \rho\left(r_{c p}\right)\right]$ of the electron density at the $(3,-1)$ bond critical point $(C P)$ is negative, emphasizing their shared shell or covalent character. ${ }^{1}$ Bonds in $\mathrm{SO}_{2} \mathrm{CN}$ fragment shared by the studied molecules exhibit the same topological characteristics as shown in Table 3. Laplacian values $\left[\nabla^{2} \rho\left(r_{c p}\right)\right]$ for S-O bonds are highly negative in the range from -25.9 to -36.5 e. $\AA^{-5}$; the electron density peaks around $2.9 \mathrm{e} . \AA^{-3}$ at the CPs are located slightly closer to the sulfur atom. Critical point positions for the S-N bond in the three sulfathiazole molecules (two molecules for polymorph III and one for polymorph IV) shift closer to the nitrogen atoms than in the three piroxicam molecules with higher Laplacian and electron density magnitudes; this holds true for the S-C bond. The $\mathrm{N}-\mathrm{C}$ bonds in zwitterionic piroxicam (zPX) exhibit different electron density characteristics than those found in the neutral form (nPX): higher at CPs of N2-C11 bonds and lower at CPs around the pyridine nitrogen atom. The proton transfer also influences the characteristics of the $\mathrm{C}=\mathrm{O}$ double bonds: $\mathrm{C} 2=\mathrm{O} 3$ bonds have more negative Laplacian values -31.9 and -33.1 e. $\AA^{-5}$ with much higher electron densities corresponding to 2.67 and 2.62 e. $\AA^{-3}$ at CPs in $\mathrm{zPX}$, while $\mathrm{C} 10=\mathrm{O} 4$ bond displays similar topological characteristics for the three molecules.
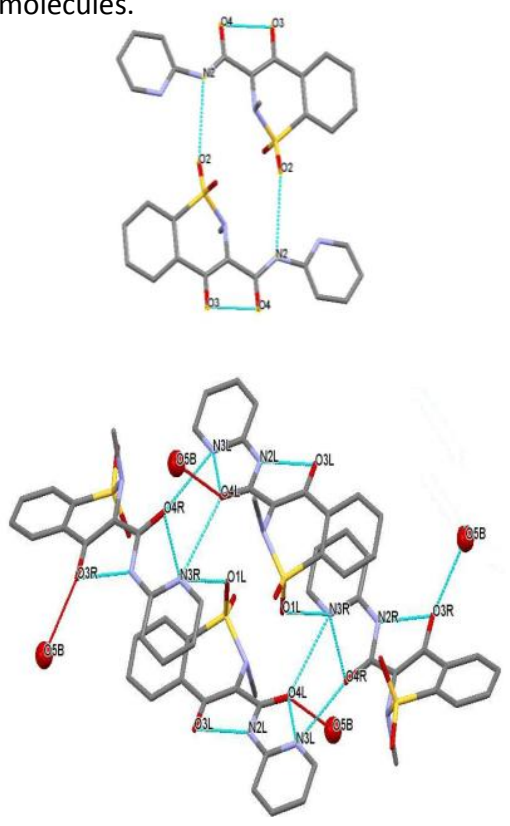

Fig. 2 Main hydrogen bonds in the crystal lattices of nPX (up) and zPX (down, $L$ and $R$ refer to left and right molecules, the oxygen atoms of the water molecule are in ball). Hydrogen atoms are omitted for clarity.

Table 3 Topology of the experimental electron density of piroxicam (nPX, zPXL and zPXR). Values in italic correspond to the sulfathiazole polymorphs $\mathrm{III}$ and IV. $\mathrm{E}_{\mathrm{HB}}$ (in $\mathrm{kJ} / \mathrm{mol}$ ) indicates the hydrogen bond energy. 
The ellipticity $\varepsilon$ is a measure of the anisotropy of the electron

\begin{tabular}{llllll}
\hline Bond D-H...A & $\begin{array}{l}\mathrm{d}(\mathrm{CP}-\mathrm{A}) \\
(\AA)\end{array}$ & $\begin{array}{l}\mathrm{d}(\mathrm{CP}-\mathrm{H}) \\
(\AA)\end{array}$ & $\begin{array}{l}\rho\left(\mathbf{r}_{\mathrm{cp}}\right) \\
\left(\mathrm{e}^{-3}\right)\end{array}$ & $\begin{array}{l}\nabla^{2} \rho\left(\mathbf{r}_{\mathrm{cp}}\right) \\
\left(\mathrm{e} \AA^{-5}\right)\end{array}$ & $\begin{array}{l}E_{\mathrm{HB}} \\
(\mathrm{kJ} / \mathrm{mol})\end{array}$ \\
\hline H-bonds nPX & & & & & \\
O3-H30...O4 & 1.108 & 0.622 & 0.32 & 3.4 & -15.1 \\
$\mathrm{~N} 2-\mathrm{H} 2 \mathrm{~N} \ldots \mathrm{O} 2$ & 1.351 & 0.952 & 0.08 & 1.3 & -2.7 \\
\hline H-bonds zPX & & & & & \\
N2L-H2NL...O3L & 1.071 & 0.642 & 0.47 & 2.6 & -23.9 \\
N2R-H2NR...O3R & 1.114 & 0.666 & 0.34 & 3.2 & -16.1 \\
N3L-H3NL...O4L & 1.216 & 0.771 & 0.19 & 2.5 & -7.3 \\
N3R-H3NR...O1L & 1.426 & 1.262 & 0.06 & 1.0 & -1.7 \\
N3R-H3NR...O4R & 1.195 & 0.735 & 0.20 & 3.1 & -8.5 \\
O5B-H5OB...O3R & 1.176 & 0.663 & 0.15 & 3.7 & -7.2 \\
O5B -H6OB...O4L & 1.210 & 0.675 & 0.14 & 3.3 & -6.3 \\
O5A -H5OA...O5B & 1.270 & 0.713 & 0.10 & 2.7 & -4.7 \\
N3L -H3NL...O4R & 1.245 & 0.808 & 0.12 & 2.2 & -4.7 \\
N3R -H3NR...O4L & 1.245 & 0.808 & 0.12 & 2.2 & -4.7 \\
\hline
\end{tabular}

density in the atomic bonds; $\varepsilon=0$ indicates no $\pi$-character of the bond and a large value of $\varepsilon$ denotes a substantial amount of $\pi$ bonding. For the studied molecules including sulfathiazole polymorphs, C-C and $\mathrm{C}-\mathrm{N}$ bonds in the aromatic rings exhibit expected large values of $\varepsilon$; the highest values were found for $\mathrm{C} 1-\mathrm{C} 2$, C1-C10, N2-C10 and N2-C11 as indicated in Table 3. In contrast, the bonds of sulfonyl cyanide fragment have weak ellipticities except S1-C8 of the sulfathiazole molecules. In the resonant form depicts in Scheme $1 \mathrm{~b}$, the $\mathrm{C} 1-\mathrm{C} 10$ and $\mathrm{C} 10-\mathrm{N} 2$ bond distances are drawn as single bond, nevertheless the ellipticity of the corresponding bonds are clearly different from zero. Therefore, the resonant form which better represents the experimental results is drawn in Scheme 3.<smiles></smiles>

Scheme 3 Resonant form of $\mathrm{zPX}$ in agreement with the experimental results.

The Laplacian at the bond critical point is positive (closed-shell character) ${ }^{1}$ for hydrogen bonds and intermolecular contacts given in Table 3. The ellipticity $\varepsilon$ is not given for these hydrogen contacts since it is an index of the $\sigma$ character of covalent bonds. Both Laplacien and density values are indicators of the bond strength; the intramolecular contacts are stronger than intermolecular ones. The intramolecular contact $\mathrm{O} 4 \ldots \mathrm{H} 30$ in $\mathrm{nPX}, \mathrm{O} 3 \mathrm{~L} . . . \mathrm{H} 2 \mathrm{NL}$ and O3R...H2NR in zPX are characterized by high values of $\nabla^{2} \rho\left(r_{\mathrm{cp}}\right)$ and $\rho\left(r_{c p}\right)$ respectively equal to $3.4,2.6,3.2$ e. $\AA^{-5}$ and $0.32,0.47,0.34$ e. $\AA^{-3}$; other intramolecular and intermolecular contacts exhibit $\nabla^{2} \rho\left(r_{\mathrm{cp}}\right)$ in the range of 1.0 to 3.7 e..$^{-5}$ (this latter value corresponds $\left[\mathrm{E}_{\mathrm{HB}}=\mathrm{V}\left(\mathrm{r}_{\mathrm{cp}}\right) / 2\right]^{40}$ are listed in the last column of Table 3. The strongest $\mathrm{O} 4 \ldots \mathrm{H} 30$ in $\mathrm{nPX}$ and $\mathrm{O} 3 \mathrm{~L} . . . \mathrm{H} 2 \mathrm{NL}, \mathrm{O} 3 \mathrm{R} . . . \mathrm{H} 2 \mathrm{NR}$ in zPX are characterized by high value of $\mathrm{E}_{\mathrm{HB}}=-15.1,-23.9,-16.1 \mathrm{~kJ} / \mathrm{mol}$. Other Table 3 (continued) contacts have much smaller energy values ranging from -1.7

\begin{tabular}{|c|c|c|c|c|c|}
\hline Bond A-B & $\begin{array}{l}\mathrm{d}(\mathrm{CP}-\mathrm{A}) \\
(\AA)\end{array}$ & $\begin{array}{l}\text { d(CP-B) } \\
(\AA)\end{array}$ & $\begin{array}{l}\rho\left(\mathbf{r}_{\mathrm{cp}}\right) \\
\left(\mathrm{e} \AA^{-3}\right)\end{array}$ & $\begin{array}{l}\nabla^{2} \rho\left(\mathbf{r}_{\mathrm{cp}}\right) \\
\left(\mathrm{e} \AA^{-5}\right)\end{array}$ & $\varepsilon$ \\
\hline \multirow[t]{6}{*}{ S-O1 } & 0.685 & 0.750 & 2.86 & -27.8 & 0.07 \\
\hline & 0.688 & 0.746 & 2.79 & -25.9 & 0.06 \\
\hline & 0.708 & 0.727 & 2.90 & -27.0 & 0.04 \\
\hline & 0.678 & 0.772 & 2.74 & -32.1 & 0.10 \\
\hline & 0.706 & 0.745 & 2.76 & -27.8 & 0.02 \\
\hline & 0.716 & 0.734 & 2.82 & -26.3 & 0.11 \\
\hline \multirow[t]{6}{*}{$\mathrm{S}-\mathrm{O} 2$} & 0.695 & 0.737 & 2.89 & -28.6 & 0.09 \\
\hline & 0.715 & 0.719 & 2.90 & -28.0 & 0.06 \\
\hline & 0.704 & 0.733 & 2.83 & -26.0 & 0.09 \\
\hline & 0.720 & 0.728 & 2.98 & -36.5 & 0.04 \\
\hline & 0.725 & 0.714 & 2.94 & -29.9 & 0.01 \\
\hline & 0.708 & 0.731 & 2.87 & -28.4 & 0.05 \\
\hline \multirow[t]{6}{*}{ S1-N1 } & 0.881 & 0.764 & 1.86 & -6.8 & 0.09 \\
\hline & 0.886 & 0.747 & 1.94 & -6.9 & 0.08 \\
\hline & 0.886 & 0.745 & 1.94 & -6.5 & 0.09 \\
\hline & 0.876 & 0.715 & 2.18 & -12.8 & 0.06 \\
\hline & 0.886 & 0.717 & 2.09 & -10.5 & 0.05 \\
\hline & 0.891 & 0.711 & 2.09 & -8.2 & 0.11 \\
\hline \multirow[t]{6}{*}{ S1-C8 } & 1.024 & 0.722 & 1.49 & -6.1 & 0.08 \\
\hline & 1.031 & 0.732 & 1.42 & -5.1 & 0.08 \\
\hline & 1.017 & 0.739 & 1.51 & -6.2 & 0.09 \\
\hline & 1.066 & 0.694 & 1.57 & -7.6 & 0.15 \\
\hline & 1.056 & 0.703 & 1.55 & -7.2 & 0.14 \\
\hline & 1.039 & 0.722 & 1.50 & -6.1 & 0.12 \\
\hline \multirow[t]{3}{*}{ N1-C9 } & 0.842 & 0.644 & 1.66 & -5.6 & 0.04 \\
\hline & 0.836 & 0.641 & 1.70 & -7.6 & 0.06 \\
\hline & 0.840 & 0.638 & 1.74 & -8.4 & 0.08 \\
\hline \multirow[t]{3}{*}{ N2-C10 } & 0.805 & 0.551 & 2.25 & -22.5 & 0.25 \\
\hline & 0.804 & 0.588 & 2.13 & -18.7 & 0.15 \\
\hline & 0.813 & 0.575 & 2.12 & -20.0 & 0.19 \\
\hline \multirow[t]{3}{*}{ N2-C11 } & 0.823 & 0.583 & 2.00 & -15.3 & 0.21 \\
\hline & 0.770 & 0.584 & 2.37 & -22.5 & 0.20 \\
\hline & 0.788 & 0.575 & 2.23 & -20.0 & 0.24 \\
\hline \multirow[t]{3}{*}{ N3-C11 } & 0.785 & 0.553 & 2.38 & -21.9 & 0.13 \\
\hline & 0.801 & 0.546 & 2.28 & -23.5 & 0.22 \\
\hline & 0.809 & 0.535 & 2.26 & -22.7 & 0.22 \\
\hline \multirow[t]{3}{*}{ N3-C15 } & 0.772 & 0.568 & 2.40 & -21.7 & 0.12 \\
\hline & 0.852 & 0.503 & 2.18 & -23.0 & 0.16 \\
\hline & 0.836 & 0.520 & 2.19 & -22.6 & 0.18 \\
\hline \multirow[t]{3}{*}{$\mathrm{O} 3-\mathrm{C} 2$} & 0.801 & 0.532 & 2.23 & -20.2 & 0.09 \\
\hline & 0.802 & 0.466 & 2.67 & -31.9 & 0.06 \\
\hline & 0.798 & 0.480 & 2.62 & -33.1 & 0.13 \\
\hline \multirow[t]{3}{*}{$\mathrm{O} 4-\mathrm{C} 10$} & 0.790 & 0.458 & 2.75 & -31.5 & 0.07 \\
\hline & 0.806 & 0.446 & 2.69 & -28.6 & 0.09 \\
\hline & 0.787 & 0.454 & 2.84 & -34.3 & 0.11 \\
\hline \multirow[t]{3}{*}{$\mathrm{C} 1-\mathrm{C} 2$} & 0.681 & 0.691 & 2.26 & -21.0 & 0.36 \\
\hline & 0.702 & 0.713 & 2.09 & -17.6 & 0.36 \\
\hline & 0.676 & 0.727 & 2.12 & -18.8 & 0.39 \\
\hline \multirow[t]{3}{*}{ C1-C10 } & 0.743 & 0.727 & 1.90 & -14.8 & 0.24 \\
\hline & 0.701 & 0.727 & 2.04 & -16.8 & 0.33 \\
\hline & 0.700 & 0.741 & 2.00 & -16.5 & 0.33 \\
\hline \multirow[t]{3}{*}{$\mathrm{N} 2-\mathrm{H} 2 \mathrm{~N}$} & 0.658 & 0.232 & 2.55 & -32.3 & 0.07 \\
\hline & 0.717 & 0.201 & 2.25 & -28.8 & 0.03 \\
\hline & 0.718 & 0.204 & 2.26 & -29.9 & 0.05 \\
\hline \multirow[t]{2}{*}{ N3-H3N } & 0.749 & 0.198 & 2.28 & -36.4 & 0.04 \\
\hline & 0.738 & 0.201 & 2.29 & -35.1 & 0.04 \\
\hline O3-H30 & 0.731 & 0.160 & 2.42 & -45.9 & 0.01 \\
\hline
\end{tabular}

(intermolecular $01 \mathrm{~L} . . . \mathrm{H} 3 \mathrm{NR}$ ) to $-8.5 \mathrm{~kJ} / \mathrm{mol}$ (intramolecular O4R...H3NR). Compared to $\mathrm{nPX}$, the $\mathrm{ZPX}$ crystal lattice exhibits numerous hydrogen intermolecular bonds mainly due to the presence of water molecules. The only intermolecular N2$\mathrm{H} 2 \mathrm{~N} \ldots \mathrm{O} 2$ hydrogen bond in $\mathrm{nPX}$ compound is characterized by a weak $E_{\mathrm{HB}}$ interaction energy $(-2.7 \mathrm{~kJ} / \mathrm{mol})$. As a comparison, in $\mathrm{ZPX}$ crystal five intermolecular hydrogen bonds (last lines in Table 3 ) with energy values ranging from -4.7 to $-7.2 \mathrm{~kJ} / \mathrm{mol}$. This shows that a high crystal energy (see below the energy section) can be expected for zPX crystal. 


\section{Atomic charges and dipole moments}

In Table 4 are given the integrated charges over the atomic basins obtained for $\mathrm{nPX}$ and $\mathrm{zPX}$ compound using the Bader's method. ${ }^{1}$ The charges of $\mathrm{S}$ (1.85 e in average) and $\mathrm{O} 1$ (-1.06 e) and $\mathrm{O} 2$ (-1.0 e) of the $\mathrm{SO}_{2}$ groups are very comparable and stay unchanged for the three molecules. These values are consistent with those found in the sulfonyl cyanide group of the sulfathiazole polymorphs as shown in Table 4. Surprisingly, the proton transfer ( $\mathrm{H} 3 \mathrm{O}$ with a charge of $0.61 \mathrm{e}$ in $\mathrm{nPX}$ molecule) does not seem to really affect the charges of $\mathrm{O} 3$ and $\mathrm{O} 4$ oxygen atoms (-1.02 to $-1.12 \mathrm{e})$. However, the charge of C2 carbon atom is higher in zPX molecules (0.76 e in averaged) than in $\mathrm{nPX}$ one (0.59 e). In addition, the nitrogen N3 charges are different for $n P X(-0.93$ e) and $z P X(-1.16$ e for $z P X L$ and -1.05 e for $\mathrm{nPXR}$ ); the charges of attached $\mathrm{H} 3 \mathrm{~N}$ are similar for $\mathrm{ZPXL}$ and $z P X R$ and very high $(0.52 \mathrm{e})$. Furthermore, the summation of the charges beared by the $\mathrm{O} 3, \mathrm{O} 4, \mathrm{~N} 2$ and N3 is more negative for the zwitterionic forms than for the neutral one $(-3.93$ e for $\mathrm{nPX}$; -4.34 e for $z P X L$ and -4.22 e for $z P X R)$ in agreement with the resonant form present in Scheme 3.

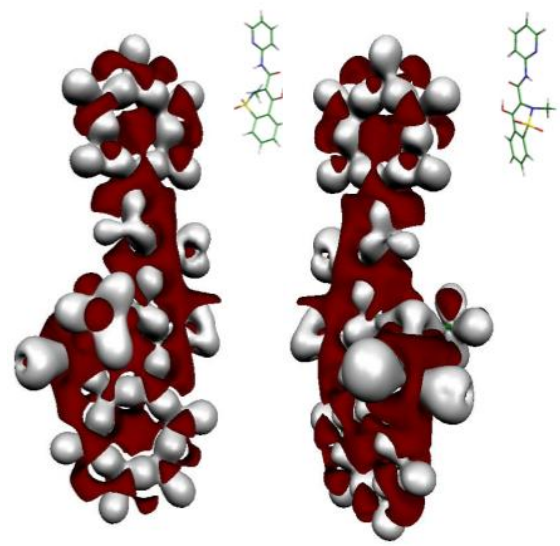

Fig. 3 Static deformation density of $\mathrm{nPX}$ molecule (two orientations). Isovalue surface cutoffs are $\pm 0.01 \mathrm{e}^{-3}$. Positive density is in grey and negative density is in red.

The hydrogen atom $\mathrm{H} 2 \mathrm{~N}$ have different charges in the two compounds ( $0.33 \mathrm{e}$ in $\mathrm{nPX}$ and $0.42 \mathrm{e}$ in $\mathrm{zPX}$ ) whereas the charge magnitude of $\mathrm{N} 2$ is slightly higher in $\mathrm{ZPX}$ molecules $(-0.98 \mathrm{e}$ in $\mathrm{ZPXL}$ and $-1.02 \mathrm{e}$ in $\mathrm{ZPXR}$ ) than in $\mathrm{nPX}$ molecule (-0.94 e).

In the bottom of Table 4 are listed the dipole moment magnitudes found for the three molecules. The values of the dipoles are quiet different: 9.1 D for nPX, 6.8 D and 22.7 D for the two molecules of $\mathrm{zPX}$. This has to be compared with the weak value found by AbuEittah et al. ${ }^{41}$ from an ab initio calculation in the gaz state, for which the geometry of the $\mathrm{nPX}$ has been optimized (2.2 D). The respective orientation of the $\mathrm{C} 9$ methyl atom with respect to $\mathrm{SO}_{2}$ group considerably enhances the dipole moment of the zPXR molecule. The total charge and dipole moment for the sulfonyl cyanide group are also given in Table 4. The charges of the sulfonyl cyanide fragment are slightly higher in the sulfathiazole polymorphs $(-1.20 \mathrm{e}$ in average) than those found in the piroxicam molecules (-0.93 e in average). For the same chemical group, the dipole moment magnitudes are different for the PX compounds, the lowest value was found for $\mathrm{nPX}(9.28 \mathrm{D})$ and the highest for ZPXR (13.64 D). Comparatively, in the sulfathiazole polymorphs, the dipole
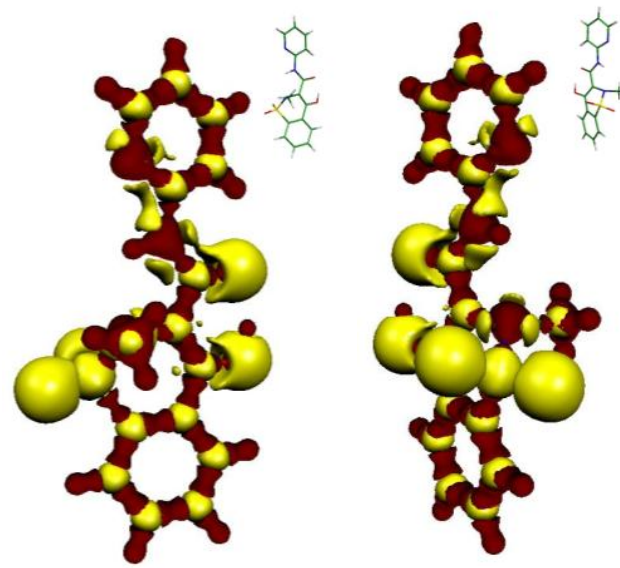

Fig. 4 Laplacian $\left[\nabla^{2} \rho(\mathbf{r})\right]$ of the electron density of $n P X$ molecule (two orientations as in Fig. 3). Isovalue surface cutoffs are $\pm 0.3 \mathrm{eA}^{-5}$. Positive Laplacian is in yellow and negative Laplacian is in red.

moments are close in a range of values from $11.19 \mathrm{D}$ (form III) to 12.34 D (form IV). In order to illustrate the charge repartition in the two piroxicam compounds, we have cut the molecules in two parts at the $\mathrm{C} 1-\mathrm{C} 10$ bond level as shown in Figure 5 . In the nPX molecule, the two parts have dipole moment values of $1.91 \mathrm{D}$ (pyridinecontaining fragment) and $9.16 \mathrm{D}$ (sulfonyl-cyanide-containing fragment). When the proton transfer occurs, this latter group has smaller dipole magnitudes equal to $5.11 \mathrm{D}$ and $4.32 \mathrm{D}$ for $\mathrm{ZPXL}$ and $z P X R$, respectively. The dipole values of the pyridine-containing fragment in the $z P X$ molecules are higher than that of $n P X$ molecule and reach 7.0 D (zPXL) and 20.74 D (zPXR).

\section{Electrostatic potential}

The electrostatic potential features for $\mathrm{nPX}$ and $\mathrm{zPX}$ molecules are shown in Figure 6. Positive isovalue $\left(+0.2 \mathrm{e}^{-1}\right)$ surface is depicted in grey color and negative isovalue surface $\left(-0.1 \mathrm{e}^{-1}\right)$ is in red. This last surface surrounds the negatively charged atoms as oxygen and nitrogen ones. However, the negative region of the electrostatic potential is more extended for $\mathrm{ZPX}$ molecule in comparison to $\mathrm{nPX}$ one. This reveals a more pronounced chemical reactivity for the zwitterionic piroxicam, even though the strict minima of the potential $\left(-0.24 \mathrm{e} \AA^{-1}\right.$ for $n P X,-0.25 e \AA^{-1}$ for $z P X L$ and $-0.28 e \AA^{-1}$ for $z P X R)$ are not very different. The zwitterionic character of the piroxicam is also revealed by the extended surface of the positive electrostatic potential around the pyridyl group; this is more evident for ZPXR molecules and can be related to the high value found for the dipole moment. Another way to quantitatively compare the features of the electrostatic potential is to use the statistical descriptors defined by Politzer et al. ${ }^{23-26}$ and described in the methodological section. The electrostatic potential is projected on the isodensity surface $\left(0.007 \mathrm{e}^{-3}\right)$ taken as a molecular surface.

The surface is meshed ${ }^{42}$ then the value of the electrostatic potential is estimated for each point of the mesh. ${ }^{43-44}$ Table 5 lists the main statistical characteristics found for the three molecules of this study. Among these molecules, zPXR presents the highest statistical characteristics. This is revealed by high values of $V_{\max }\left(0.54 \mathrm{e}^{-1}\right)$ and $V_{\min }\left(-0.27 e^{-1}\right)$ compared to $\mathrm{nPX}\left(0.35\right.$ and $\left.-0.23 \mathrm{e} \AA^{-1}\right)$ and $z P X L$ $\left(0.31\right.$ and $\left.-0.24 e^{-1}\right)$; this also holds true for the average positive 
Table 4 Atomic charges (in e unit) and dipole moment values (in Debye) of $\mathrm{nPX}, \mathrm{zPXL}$ and zPXR. Comparisons are made to sulfathiazole (S) polymorphs.

\begin{tabular}{|c|c|c|c|c|c|c|}
\hline Atom & nPX & zPXL & zPXR & S-IIIA & S-IIIB & S-IV \\
\hline S1 & 1.85 & 1.91 & 1.78 & 1.87 & 1.73 & 1.65 \\
\hline $\mathrm{O} 1$ & -1.17 & -1.05 & -0.95 & -1.06 & -1.02 & -1.07 \\
\hline $\mathrm{O} 2$ & -1.00 & -0.94 & -1.05 & -1.13 & -1.03 & -1.04 \\
\hline $\mathrm{O} 3$ & -1.04 & -1.08 & -1.08 & & & \\
\hline $\mathrm{O} 4$ & -1.02 & -1.12 & -1.07 & & & \\
\hline $\mathrm{N} 1$ & -0.75 & -0.75 & -0.83 & -0.80 & -0.83 & -0.83 \\
\hline $\mathrm{N} 2$ & -0.94 & -0.98 & -1.02 & & & \\
\hline N3 & -0.93 & -1.16 & -1.05 & & & \\
\hline $\mathrm{C} 1$ & 0.11 & 0.08 & 0.15 & & & \\
\hline $\mathrm{C} 2$ & 0.59 & 0.79 & 0.72 & & & \\
\hline $\mathrm{C} 3$ & 0.19 & -0.10 & 0.04 & & & \\
\hline $\mathrm{C} 4$ & -0.14 & -0.10 & -0.01 & & & \\
\hline C5 & 0.20 & -0.04 & 0.04 & & & \\
\hline C6 & 0.09 & -0.05 & 0.05 & & & \\
\hline C7 & -0.01 & 0.02 & -0.01 & & & \\
\hline C8 & 0.18 & -0.01 & -0.02 & 0.05 & -0.05 & 0.00 \\
\hline C9 & 0.40 & 0.44 & 0.36 & & & \\
\hline $\mathrm{C} 10$ & 1.29 & 1.18 & 1.14 & & & \\
\hline $\mathrm{C} 11$ & 0.79 & 0.76 & 0.86 & & & \\
\hline $\mathrm{C} 12$ & 0.00 & -0.05 & -0.05 & & & \\
\hline $\mathrm{C} 13$ & 0.02 & 0.01 & 0.13 & & & \\
\hline C14 & -0.12 & -0.06 & 0.04 & & & \\
\hline $\mathrm{C} 15$ & 0.58 & 0.43 & 0.36 & & & \\
\hline $\mathrm{H} 3$ & -0.02 & 0.08 & 0.00 & & & \\
\hline $\mathrm{H} 4$ & 0.03 & 0.05 & 0.05 & & & \\
\hline H5 & 0.05 & 0.10 & 0.04 & & & \\
\hline H6 & 0.05 & 0.16 & 0.05 & & & \\
\hline H9A & -0.08 & 0.01 & 0.12 & & & \\
\hline H9B & -0.11 & 0.08 & 0.10 & & & \\
\hline $\mathrm{H} 9 \mathrm{C}$ & 0.00 & 0.10 & 0.13 & & & \\
\hline H12 & 0.08 & 0.15 & 0.17 & & & \\
\hline H13 & -0.06 & -0.01 & -0.04 & & & \\
\hline H14 & 0.03 & 0.08 & 0.00 & & & \\
\hline H15 & -0.06 & 0.02 & -0.01 & & & \\
\hline $\mathrm{H} 2 \mathrm{~N}$ & 0.33 & 0.42 & 0.43 & & & \\
\hline $\mathrm{H} 3 \mathrm{O}$ & 0.61 & & & & & \\
\hline $\mathrm{H} 3 \mathrm{~N}$ & & 0.53 & 0.52 & & & \\
\hline $\begin{array}{l}\text { Molecular } \\
\text { dipole }\end{array}$ & 9.12 & 6.83 & 22.69 & & & \\
\hline $\begin{array}{l}\mathrm{SO}_{2} \mathrm{CN} \\
\text { charge }\end{array}$ & -0.89 & -0.84 & -1.07 & -1.07 & -1.20 & -1.28 \\
\hline $\begin{array}{l}\mathrm{SO}_{2} \mathrm{CN} \\
\text { dipole }\end{array}$ & 9.28 & 10.88 & 13.64 & 11.19 & 11.18 & 12.34 \\
\hline
\end{tabular}

and negative potential on the surface $\left(0.18 /-0.11 \mathrm{e}^{-1}\right.$ compared to $0.09 /-0.08 \mathrm{e}^{-1}$ for $\mathrm{nPX}$ and $0.09 /-0.09 \mathrm{e}^{-1}$ for $\left.\mathrm{ZPXL}\right)$. The high polarity detected on the surface of the $\mathrm{ZPXR}$ molecule is also illustrated by the indices $\Pi$ (equal to 0.15 compared to 0.08 (nPX) and 0.09 (zPXL)) and $v$ (0.22 compared to 0.25 for both $\mathrm{nPX}$ and $\mathrm{zPXL}$ ). All these results are consistent with the remarkable dipole moment value found for ZPXR molecule.
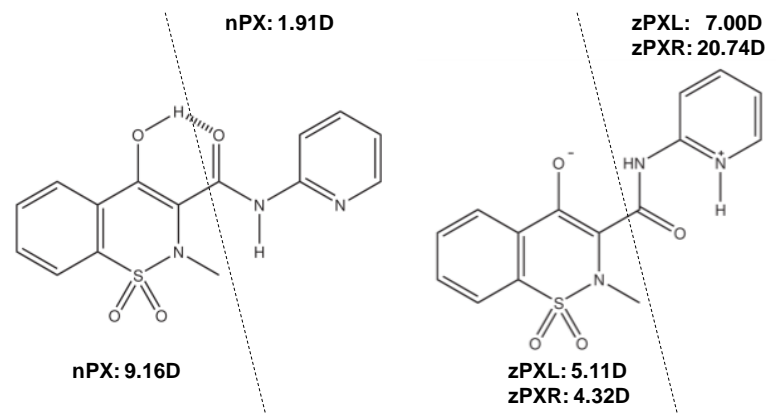

Fig. 5 The dipole moment values obtained for the two parts (separated by the dashed line) of the piroxicam molecules.

\section{Interaction energies}

The electrostatic interaction energies $E_{\text {elec }}$ were calculated using VMoPro ${ }^{37,} 38$ program. These calculations are based on the experimental electron density. The resulted values are summarized in Table 6. For $\mathrm{nPX}$ molecules grouped in a dimer through two $\mathrm{N}$ $\mathrm{H}$...O hydrogen bonds (see Figure 2), the electrostatic interaction energy was found equal to $-21.73 \mathrm{~kJ} / \mathrm{mol}$. This interaction involves one atom of the $\mathrm{SO}_{2}$ group and is weaker than that found in $\mathrm{zPX}$ crystal $\left(E_{\text {elec }}=-110.62 \mathrm{~kJ} / \mathrm{mol}\right)$ also involving one oxygen atom of the $\mathrm{SO}_{2}$ group. The difference of the electrostatic energy values can be explained by the stacking of the molecules in the two lattices: as shown in Figure 2, the interacting molecules of $\mathrm{nPX}$ are parallel and approximately in the same plane; the corresponding zPX molecules are also parallel but not in the same plane making the pyridine ring of one molecule to face the phenyl group of the other in a supplementary $\pi-\pi$ interaction. The zPXL and zPXR molecules (see Figure 2) interacting through a double hydrogen bonds (N3LH3NL...O4R and N3R-H3NR...O4L) present the highest electrostatic energy equal to $-161.55 \mathrm{~kJ} / \mathrm{mol}$. On the other hand, the electrostatic interaction energies between the water and $\mathrm{zPX}$ molecules are found equal to $-37.62 \mathrm{~kJ} / \mathrm{mol}$ (zPXR) and -29.78 $\mathrm{kJ} / \mathrm{mol}(\mathrm{PXXL})$. These values are higher than that found for the water-water interaction $(-11.21 \mathrm{~kJ} / \mathrm{mol})$.

The packing energy $E_{\text {pack }}$ including the dispersive-repulsive forces (van der Waals, hydrogen bonding) was estimated by the empirical formulae of the atom-atom potential model. ${ }^{45-47}$ This property is important since it is directly related to the dissolution rate of crystals which is fundamental for active pharmaceutical substances. In Table 6 are given the corresponding values of $E_{\text {pack }}$ for interacting molecules. The magnitudes of the packing energy are quiet different from those of experimental electrostatic interaction energy $E_{\text {elec }}$ also given in Table 6 . By summing all packing energies in the crystal lattice, we obtained the total packing energy. The values were found equal to -188.96 and $-500.0 \mathrm{kj} / \mathrm{mol}$ for $\mathrm{nPX}$ and $\mathrm{zPX}$ crystals, respectively. The twisted molecular conformations, the presence of water molecules and the numerous hydrogen bonds

Table 5 Statistical Features of The Electrostatic Potential on the Isodensity Surface $\left(0.007 \mathrm{e}^{-3}\right)$.

\begin{tabular}{lcccccccccccc}
\hline & $\mathrm{m}$ & $\mathrm{n}$ & $\overline{\mathbf{V}}_{\mathrm{S}}^{+}$ & $\overline{\mathbf{V}}_{\mathrm{S}}^{-}$ & $\overline{\mathbf{V}}_{\mathrm{S}}$ & $\Pi$ & $\sigma_{+}^{2}$ & $\sigma_{-}^{2}$ & $\sigma_{\text {tot }}^{2}$ & $v$ & $\mathrm{~V}_{\max }$ & $\mathrm{V}_{\min }$ \\
\hline $\mathrm{nPX}$ & 6122 & 2637 & 0.089 & -0.076 & 0.040 & 0.075 & 0.003 & 0.004 & 0.008 & 0.247 & 0.348 & -0.232 \\
zPXL & 4696 & 4314 & 0.086 & -0.087 & 0.003 & 0.086 & 0.004 & 0.004 & 0.008 & 0.250 & 0.306 & -0.239 \\
zPXR & 4521 & 4077 & 0.180 & -0.116 & 0.040 & 0.152 & 0.015 & 0.007 & 0.022 & 0.215 & 0.541 & -0.274 \\
\hline
\end{tabular}


in $\mathrm{ZPX}$ crystal increase considerably the lattice energy for this compound. As a comparison, for the polymorphs III and IV of sufathiazole, which some results are reported in this paper, the packing energies were found respectively equal to -258.9 and $-137.9 \mathrm{kj} / \mathrm{mol}$.

Table 6. Experimental electrostatic interaction energy $E_{\text {elec }}$ and packing energy $E_{\text {pack }}$ (in $\mathrm{kJ} / \mathrm{mol}$ ) of piroxicam molecules. $A$ and $B$ are the water molecules in the $\mathrm{PX}$ crystal.

\begin{tabular}{|c|c|c|c|}
\hline nPX & interactions & $E_{\text {elec }}$ & $E_{\text {pack }}$ \\
\hline dimer $(2-x,-y,-z)$ & $2 \times(\mathrm{H} 2 \mathrm{~N} \ldots \mathrm{O} 2)$ & -21.73 & -73.3 \\
\hline \multicolumn{4}{|l|}{ zPX } \\
\hline dimer $\mathbf{R}-\mathbf{L}(x, y, z)$ & H3NR...O1L & -110.62 & -68.7 \\
\hline $\mathbf{B}-\mathbf{R}(x, y, z)$ & $\mathrm{H} 5 \mathrm{OB} \ldots \mathrm{O} 3 \mathrm{R}$ & -37.62 & -26.8 \\
\hline B-L $(x, y, l+z)$ & H6OB...O4L & -29.78 & -26.5 \\
\hline dimer A-B $(1-x, 1-y, 1-z)$ & H5OA...O5B & -11.21 & -18.5 \\
\hline dimer $\mathbf{L}-\mathbf{R}(2-x, 1-y,-z)$ & $\begin{array}{l}\text { H3NL...O4R } \\
\text { H3NR...O4L }\end{array}$ & -161.55 & -86.1 \\
\hline
\end{tabular}

\section{Conclusions}

In the present study we have derived the electron density and electrostatic properties for neutral (nPX) and zwitterionic (zPX) piroxicam molecules from high resolution low temperature $X-$ ray diffraction experiments. The electron density distribution was carefully analyzed through its topological features. For covalent bonds, the topological characteristics are really consistent for all molecules. The comparison of these parameters for the $\mathrm{SO}_{2} \mathrm{CN}$ sulfonyl cyanide group with those found in 2 polymorphs of sulfathiazole molecule is excellent. According to the interatomic distances, ellipticity and charges a resonant form describing the $\mathrm{ZPX}$ behavior have been determined. The conformation and crystal environment modify the electrostatic properties like the dipole moment, which was found higher in ZPX (6.83 and 22.69 D) molecule than in nPX $(9.12$ D) one. The statistical analysis of the electrostatic potential also reveals different chemical reactivity for the piroxicam molecules. The calculations of the intermolecular electrostatic interaction energies for the three molecules of piroxicam also highlight the impacts of the molecular conformation and the proton transfer. Using an empirical atom-atom potential model, the lattice energies were estimated emphasizing the great difference in the solid properties of $\mathrm{nPX}(-187.96 \mathrm{kj} / \mathrm{mol})$ and $\mathrm{zPX}(-500 \mathrm{kj} / \mathrm{mol})$ compounds.

\section{$\mathrm{nPX}$}

$V_{\min }=-0.24 e \AA^{-1}$
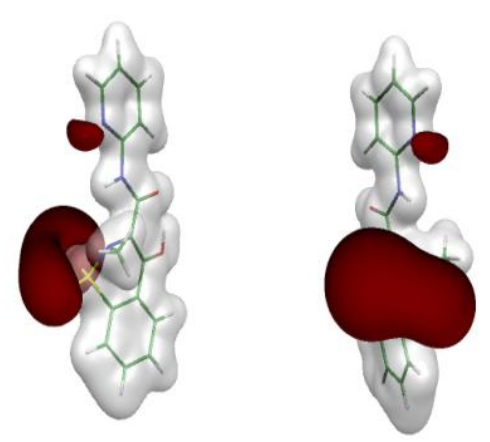

ZPXL

$V_{\min }=-0.25 e \AA^{-1}$
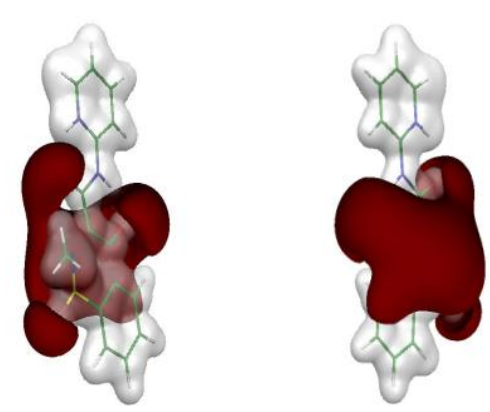

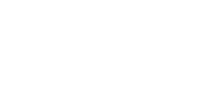

\section{zPXR}

$V_{\min }=-0.28 e \AA^{-1}$
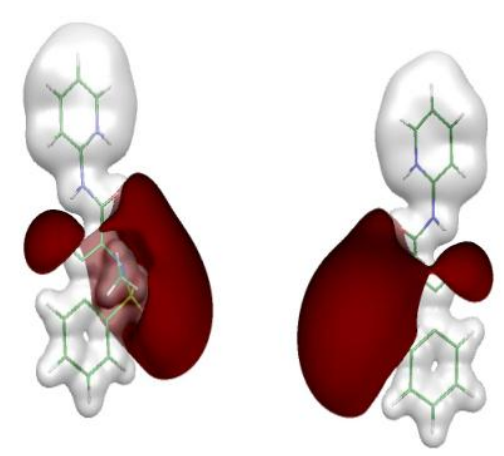

Fig. 6 Experimental electrostatic potential (two orientations as in Figure 3). Isovalue surface cutoffs are $+0.2 \mathrm{e}^{-1}$ (grey) and $-0.1 \mathrm{e} \AA^{-1}$ (red). The minimum of the electrostatic potential is also indicated. 


\section{Acknowledgements}

The CNRS, Université Paris Saclay, Université Paris Sud and CentraleSupélec are acknowledged. The authors thank ANR (Agence Nationale de la Recherche) for partial support of this work through the NPLIN-4-drug project.

\section{Notes and references}

1 R. F. W. Bader, Atoms in Molecules: A Quantum Theory Clarendon Press: Oxford, 1990.

2 N. El Hassan, A. Ikni, J.-M. Gillet, A. Spasojevic-de Biré and N. E. Ghermani, Cryst. Growth Des., 2013, 13, 7, 2887.

3 S. Datta and D. J. W. Grant, Nature Reviews Drug Discovery 2004, 3, 42

4 T. J. Carty, J. S. Stevens, J. G. Lombardino, M. J. Parry and M. J. Randall, Prostaglandins, 1980, 19, 5, 671.

5 D. Earnest, L. Hixson and D. Alberts, J. Cell. Biochem., 1992, 16I, 156.

6 J. Jinno, D. Oh, J.R. Crison and G.L. Amidon, J. Pharm. Sci., 2000, 89, 268.

7 M. Yazdanian, K. Briggs, C. Jankovsky and A. Hawi, Pharm. Res., 2004, 21, 293.

8 G.L. Amidon, H. Lennernäs, V.P. Shah and J. R. Crison, Pharm. Res., 1995, 12, 413.

9 H. S. Gwak, J. S. Choi and H. K. Choigwak, Int. J. Pharmaceutics, 2005, 297, 156

10 F. Vrecer, M. Vrbinc and A. Meden, J. Int. J. Pharm., 2003, 256, 3.

11 A. R. Sheth, S. Bates, F. X. Muller and D. J. W. Grant, Cryst. Growth \& Des., 2004, 4, 6, 1091.

12 J. Bordner, J. A. Richards, P. Weeks and E. B. Whipple, Acta Crystallogr., 1984, C40, 989-990.

13 G. Reck, G. Dietz, G. Laban, W. Günther, G. Bannier and E. Höhne, Pharmazie, 1988, 43, 7, 477.

14 M. Nyström, J. Roine, M. Murtomaa, R. M. Sankaran, H. Santos and J. Salonen, Europ. J. Pharm. Biopharm., 2015, 89, 182.

15 A. R. Sheth, J. W. Lubach, E. J. Munson, F. X. Muller and D. J. W. Grant, J. Am. Chem. Soc., 2005, 127, 6641.

16 C. Wales, L. H. Thomas and C. C. Wilson, CrystEngComm, 2012, 14, 7264.

17 S. L. Childs and K. I. Hardcastle, Cryst. Growth \& Des., 2007, 7, 7, 1291.

17 bis H. Favre, W. Powell, Nomenclature of Organic Chemistry. IUPAC Recommendations and Preferred Name 2013. Cambridge, UK: The Royal Society of Chemistry, 2013. ISBN

978-0-85404-182-4.

18 K. Fucke, S.A. Myz, T. P. Shakhtshneider, E.V. Boldyreva and

U. J. Griesser, New J. Chem., 2012, 3610, 1969.

19 The Cambridge Structural Database: A quarter of a million crystal structures and rising. F.H. Allen, Acta Crystallogr., 2002, B58, 380.

20 A. Misnev and G. Kiselovs, Z. Naturforsch., 2013, 68b, 168.

21 I. Sovago, M. J. Gutmann, J. G. Hill, H. M. Senn, L. H. Thomas,

C. C. Wilson and L. J. Farrugia, Cryst. Growth \& Des., 2014, 14, 3,1227.

22 A. L.Bingham, D. S.Hughes, M. B.Hursthouse, R. W.Lancaster, S. Tavener and T. L. Threlfall, Chem. Commun., 2001, 603.

23 P. Politzer, J. S. Murray and P. Flodmark, J. Phys. Chem., 1996, 100, 5538.

24 J. S. Murray, T. Brinck and P. Politzer, Chem. Phys., 1996, 204, 289.

25 P. Politzer and J. S. Murray, J. Phys. Chem., 1998, 102, 1018.

26 J. S. Murray and P. Politzer, J. Mol. Struct. : THEOCHEM, $1998,425,107$
27 J. Bordner, J. A. Richards, P. Weeks and E. B. Whipple, Acta Crystallogr., 1984, C40, 989.

28 APEX2/SAINT software Bruker AXS Inc: Madison, Wisconsin, 2013.

29 R. H. J. Blessing, Appl. Crystallogr., 1997, 30, 421.

30 A. Altomare, G. Cascarano, C. Giacovazzo and A. Guagliardi, J. Appl. Cryst., 1994, 27, 435.

31 G. M. Sheldrick, Acta Crystallogr., 2008, A64, 112.

32 L. J. Farrugia, J. Appl. Cryst., 1999, 32, 837.

33 N. K. Hansen and P. Coppens, Acta Crystallogr., 1978, A34, 909.

34 E. Clementi and C. Roetti, Atomic data and Nuclear data tables Academic press: New York, USA, 1974, 14, 177.

35 E. Clementi and D. L. Raimondi, J. Chem. Phys., 1963, 41, 2686.

36 P. M. Dominiak and P. Coppens, Acta Crystallogr., 2006, A62, 224.

37 B. Guillot, L. Viry, R. Guillot, C. Lecomte and C. Jelsch, J. Appl. Crystallogr., 2000, 34, 214.

38 C. Jelsch, B. Guillot, A. Lagoutte and C. Lecomte, J. Appl. Crystallogr., 2005, 38, 38.

39 a) A. Madsen, J. Appl. Crystallogr., 2006, 39, 757. B) P. Munshi, A. Madsen, M. A. Spackman, S. Larsen, R. Destro, Acta Crystallogr., 2008, A64, 465.

40 E. Espinosa, E. Molins and C. Lecomte, Chem. Phys. Lett., 1998, 285, 170.

41 R. H. Abu-Eittah and W. A. Zordok, J. Mol. Struct.: THEOCHEM, 2010, 951, 14.

$42 \mathrm{~S}$. Portmann and H. P. Lüthi, MOLEKEL: An Interactive Molecular Graphics Tool, Chimia, 2000, 54, 766.

43 N. E. Ghermani, N. Bouhmaida and C. Lecomte, ELECTROS, STATDENS, FIELD+: Computer programs to calculate electrostatic properties from high resolution X-ray diffraction: Internal report UMR CNRS 7036, Université Henri Poincaré, Nancy 1, France UMR CNRS 8612, Université Paris Sud, France and Université Cadi Ayyad, Morocco, 1992-2009.

44 N. Bouhmaida and N. E. Ghermani, J. Chem. Phys., 2005, 122, $11,114101$.

45 A. Gavezzotti, Acc. Chem. Res., 1994, 27(10), 309.

46 A. Gavezzotti and G. Filippini, J. Phys. Chem., 1994, 98(18), 4831.

47 S. L. Price, Chem. Soc. Rev., 2014, 43, 2098. 